\title{
Management of genetic diversity using gene dropping method based on pedigree information
}

\author{
Majid Khaldari', Ardeshir Nejati Javaremi², Abbas Pakdel ${ }^{2}$, Hasan Mehrabani Yeganeh² \\ and Peer Berg ${ }^{3}$
}

'Department of Animal Science, Faculty of Agriculture, Lorestan University, Khorram-Abad, Iran, ${ }^{2}$ Department of Animal Science, Faculty of Agriculture, University of Tehran, Karaj, Iran, ${ }^{3}$ Department of Genetics and Biotechnology, Faculty of Agricultural Sciences, Aarhus University, Research Center Foulum, Tjele, Denmark

\begin{abstract}
Preservation of genetic diversity in populations is an important task to ensure a possible longterm response to selection in animal breeding. The purpose of this study was to consider how pedigree analysis and gene dropping method could be used for management plans in order to maintain genetic variation in a population under selection of Japanese quail. Therefore, the distributions of alleles frequencies originated from founders were estimated on an actual pedigree using gene dropping simulation software. Then, genetic contribution of founders to the current population, components such as the F-statistics and effective population size were estimated. The results show that from 156 founders there are only 64 of them (22 males and 42 females) in the last generation. The average genetic contribution of a founder male and female contributing to the last generation were 1.87 and $1.40 \%$, respectively. A total of 87 and $95 \%$ of the genome in the last generation were constituted by 34 and 42 founders, respectively. The effective population size decreased as inbreeding increases. The allele frequency averaged over replicates agreed with the genetic contribution. Some useful information regarding the management of genetic diversity such as the probability of allele extinction, the probability of alleles surviving at a critically low frequency and risk of future allele extinction were derived by using these distributions. Results show that pedigree analysis and gene dropping are valuable tools in optimizing decisions to preserve genetic variability.
\end{abstract}

Keywords: gene dropping, selection, genetic diversity, founder, Japanese quail

Archiv Tierzucht 56 (2013) 50, 518-526

doi: $10.7482 / 0003-9438-56-050$

Corresponding author:

Majid Khaldari; email: khaldari@ut.ac.ir

Department of Animal Science, Faculty of Agriculture, Lorestan University, PO Box 465, 68137-1713, Khorram-Abad, Iran

(c) 2013 by the authors; licensee Leibniz Institute for Farm Animal Biology (FBN), Dummerstorf, Germany.

This is an Open Access article distributed under the terms and conditions of the Creative Commons Attribution 3.0 License (http://creativecommons.org/licenses/by/3.0/).
Received: 1 November 2012

Accepted: 19 February 2013 Online: 26 April 2013 


\section{Introduction}

Along with the enhancement of genetic progress, preservation of genetic diversity in populations is important in animal breeding. This is to ensure that a long-term response to selection for traits of interest is achievable (Barker 2001). Because of the potentially deleterious effects of loss of genetic diversity in small selected populations (Ralls et al. 1986), pedigree analysis is often recommended to allow to design breeding plans to minimize the variation in family size and maximize the genetically effective population size relative to the census population size (Lacy 1989). The expected loss of genetic variation from the populations can be minimized by increasing the number of descendants of poorly represented founders (Foose et al. 1986). Although the mean of the distribution of allele frequency for a founder should coincide with the genetic contribution computed from pedigree analysis, the probability of allele extinction can be obtained only through the gene dropping simulation (Honda et al. 2002). Gene dropping is a simulation procedure in which two unique alleles are assigned to each founder and the genotypes of all descendants along the actual pedigree are generated following the Mendelian segregation rules (MacCluer et al. 1986). However, application of this method rests on certain assumptions such as 50:50 transmission probabilities, no mutation and no migration. The method is also flexible to extend several loci and to measure the change in linkage disequilibrium (Baes \& Reinsch 2008). This allows simulating a genome for each animal where the number of repetitions refers to the number of unlinked loci (Suwanlee et al. 2007). This technique provides considerably more information about population structure than is available from calculations of the proportionate contributions of the founders (MacCluer et al. 1986). Furthermore, parameters derived from probabilities of gene origin are very useful to describe a population structure after a small number of generations, whereas the use of effective population size and inbreeding for monitoring the genetic variability over a long time period is very sensitive to the quality of available pedigree information (Pérez Torrecillas et al. 2002). The effective population size is a key parameter in conservation and population genetics because of its direct relationship with the level of inbreeding, fitness and the amount of genetic variation lost due to random genetic drift (Caballero \& Toro 2000). The purpose of this study was to consider how pedigree analysis and gene dropping methods can be used for management plans for maintaining genetic variation in a selected quail population. Therefore, by using gene dropping simulation software (Lange et al. 2001) on an actual pedigree, the distributions of frequencies of alleles originating from founders were estimated at the first and secondly, genetic contribution of founders to the current population, inbreeding and effective population size were estimated. From the distributions of frequencies of alleles, useful information for the management of genetic diversity, such as the probability of allele extinction and the probability of alleles surviving at a critically low frequency, were derived.

\section{Material and methods}

The experimental Japanese quail population (Coturnix coturnix) originated from a commercial farm in Yazd city (Iran). The population had not been selected for any traits before the start of the experiment. A total of 126 birds (generation 0 ) were randomly selected from the 
population and allowed to reproduce with the sex ratio of 1:2 (male:female) to establish a selection line. In the next generation, 30 birds more were introduced (unknown parents) into the population. These birds had then been selected for $4 \mathrm{wk}$ body weight (Khaldari et al. 2010). The number of male and female birds and contributing founders in each generation are presented in Table 1.

Table 1

The number of male and female birds, total and contributing founders in each generation of a selection experiment for $4 \mathrm{wk}$ body weight in quail

\begin{tabular}{lcccc}
\hline Generation & Male & Female & Total founder & Contributed founder \\
\hline 0 & - & - & 126 & 126 \\
1 & 162 & 175 & 30 & 113 \\
2 & 202 & 205 & - & 94 \\
3 & 204 & 206 & - & 69 \\
4 & 169 & 156 & - & 64 \\
\hline
\end{tabular}

The gene dropping simulation applied is illustrated in Figure 1, in which the process of one trial of the simulation is presented with a simple pedigree. To obtain a reliable distribution of allele frequencies in the reference population, the process was replicated 1000 times using the Mendel software (Lange et al. 2001). The probability of extinction of alleles originating from a founder $(\operatorname{Pr}($ lost)) was calculated from the proportion of replicates in which both alleles derived from the founder did not segregate in the reference population. Similarly, the probability of alleles being at high risk of extinction ( $\operatorname{Pr}($ risk)) was obtained by the proportion of replicates in which allele frequency (q) was within the range of $0<q<0.01$. The upper limit (0.01) of the range was chosen following MacCluer et al. (1986). Finally, the probability of alleles surviving at a critically low frequency, conditional on the founder alleles being retained in the reference population, was computed as:

$$
\operatorname{Pr}(\text { risk } \mid \text { survive })=\frac{\operatorname{Pr}(\text { risk })}{1-\operatorname{Pr}(\text { lost })}
$$

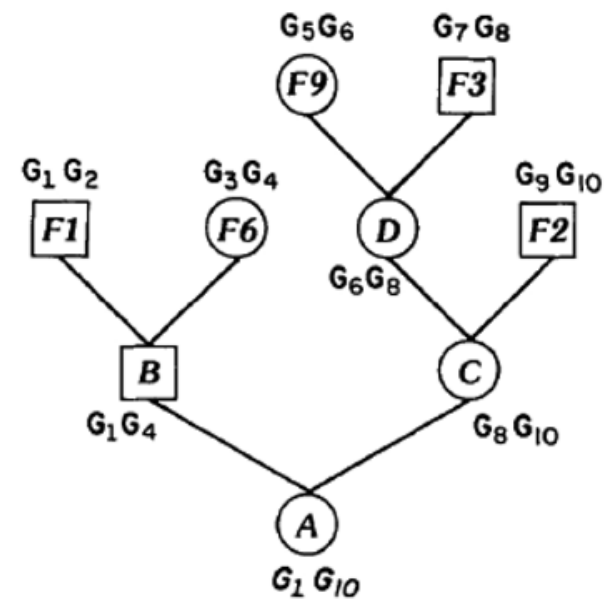

Allocation of unique hypothetical alleles $(G)$ to founders $(F)$ and genotype assign to descendants ( $A, B, C, D)$ by Mendelian segregation of founder alleles.

Figure 1

Illustration of gene dropping simulation 
This conditional probability is an indicator for the risk of future allele extinction. It should be noted that these three probabilities are conditional on the pedigree structure (Honda et al. 2002).

The contribution of founders and the inbreeding coefficients (F) for all the animals in the pedigree and F-statistics were calculated using the Eva-Inbred software 1.3 (Berg 2010). The F-statistics $\left(F_{1 T}, F_{S T}\right.$ and $\left.F_{1 S}\right)$ were estimated in each generation to assess the amount of inbreeding and the population structure. The coefficient $F_{I T}$ is the average inbreeding coefficient and $\mathrm{F}_{\mathrm{ST}}$ is the inbreeding coefficient expected under random mating. The latter was estimated as the average kinship between the sires and dams (parents) of the generation. The third coefficient $\mathrm{F}_{\mathrm{IS}}$ is the deviation from random mating obtained by the formula of Wright (Wright 1969) as:

$$
F_{I S}=\frac{F_{I T}-F_{S T}}{1-F_{S T}}
$$

The actual inbreeding $\left(\mathrm{F}_{\mathrm{IT}}\right)$ exceeds the level expected under random mating $\left(\mathrm{F}_{\mathrm{ST}}\right)$ when $\mathrm{F}_{1 \mathrm{~S}}>0$, implying that mating among more closely related parents than expected is predominant or that the population is partitioned into subpopulations and mating is more or less restricted within each subpopulation. In contrast, avoidance of inbreeding or mating between subpopulations is predominant in populations with $\mathrm{F}_{\mathrm{IS}}<0$. The effective size of the population was estimated from the increasing rate of $F_{S T}$ per generation (Caballero \& Hill 1992, Wright 1984). The generation rate of inbreeding $\left(\Delta \mathrm{F}_{\mathrm{ST}, \mathrm{g}}\right)$ of $\mathrm{F}_{\mathrm{ST}}$ was first computed as $\Delta \mathrm{F}_{\mathrm{ST}, \mathrm{t}}=\left(\mathrm{F}_{\mathrm{ST}, \mathrm{t}}\right.$ $\left.\mathrm{F}_{\mathrm{ST}, \mathrm{t}-1}\right) /\left(1-\mathrm{F}_{\mathrm{ST}, \mathrm{t}-1}\right)$, where $\mathrm{F}_{\mathrm{ST}, \mathrm{t}-1}$ and $\mathrm{F}_{\mathrm{ST}, \mathrm{t}}$ are the coefficients of $\mathrm{F}_{\mathrm{ST}}$ in two successive generations. The effective population size was then computed as $1 /\left(2 \Delta \mathrm{F}_{S T, t}\right)$ (Nomura et al. 2001). Finally, we reached to the following formula for calculating the average allele frequencies for each founder:

$$
f_{j}=\frac{S T A_{j}}{n R \times 2 N}=\sum_{i=1}^{1000} \frac{p_{i+} q_{i}}{n R}
$$

where $S T A_{j}$ is the sum of the total alleles of founder $j, n R=1000$ is the number of replicates, $N$ is the number of individuals in the last generation and $p_{i}$ and $q_{i}$ are the allele frequencies for the two alleles of founder $j$ in the last generation of replicate $i$.

\section{Results}

Descriptive statistics for the number of dropped alleles from base population into each generation are summarized in Table 2. Although the number of alleles retained in each reference population varied among replicates of simulation, the consistently small coefficient of variation implies that the average over replicates is a good indicator for the number of retained alleles. The number of birds, inbred birds, F-statistics and effective population size are presented in Table 3.

The average genetic contribution of founders to the last generation is presented in Figure 2. The results revealed that only 64 founders consisting of 22 males and 42 females contributed their genetic material to the last generation. The average genetic contribution of a male and female founder to the last generation was 1.87 and $1.40 \%$, respectively. A total of $87 \%$ of the genome in the last generation has been contributed by 34 founders, with 13 
males and 21 females contributing 37 and $50 \%$, respectively. The relative contribution of the 22 male and 42 female founders were 41.1 and $58.9 \%$, respectively.

Table 2

Descriptive statistics for the number of dropped alleles per replicate and the total number of alleles assigned to founders in each reference population $(\mathrm{Na})$

\begin{tabular}{lrrrrr}
\hline Generation & Mean & Min & Max & CV, $\%$ & Na \\
\hline 0 & 252.0 & 252 & 252 & 0 & 252 \\
1 & 288.7 & 280 & 295 & 1.2 & 60 \\
2 & 138.5 & 130 & 145 & 2.1 & - \\
3 & 85.8 & 70 & 95 & 4.2 & - \\
4 & 59.6 & 52 & 67 & 5.3 & - \\
\hline
\end{tabular}

Table 3

Number of birds, inbred birds, F-statistics and effective population size in each generation

\begin{tabular}{lcclllll}
\hline Generation & $\mathrm{N}$ & $\mathrm{N}$. inbred & \multicolumn{1}{c}{$\mathrm{F}_{\text {IT }}$} & \multicolumn{1}{c}{$\mathrm{F}_{\text {ST }}$} & \multicolumn{1}{c}{$\mathrm{F}_{\text {IS }}$} & \multicolumn{1}{c}{$\Delta \mathrm{F}$} & $\mathrm{Ne}$ \\
\hline 0 & 126 & 0 & 0 & 0 & 0 & 0 & - \\
1 & 367 & 0 & 0 & 0 & 0 & 0 & - \\
2 & 407 & 14 & 0.0086 & 0.0033 & 0.0053 & 0.0033 & 151.5 \\
3 & 410 & 67 & 0.0152 & 0.0109 & 0.0044 & 0.0076 & 65.8 \\
4 & 325 & 116 & 0.0168 & 0.0218 & -0.0051 & 0.011 & 45.5 \\
Total & 1635 & 197 & 0.0088 & & & & \\
\hline
\end{tabular}

$\mathrm{N}$ : number of birds, Ne: effective population size

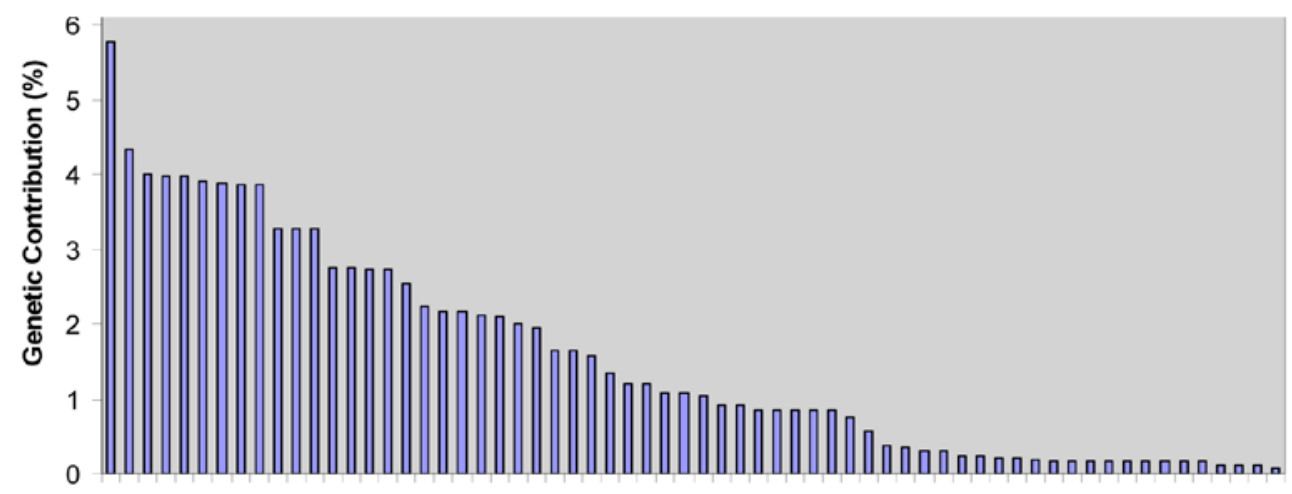

founders

Figure 2

Genetic contributions (\%) of 64 retained founders in the last generation

A more detailed description of extreme founders contributing to the last generation is presented in Table 4. It can be seen that the genetic contribution based on the pedigree is a good estimate of the realized contribution. It is also evident that all founders still segregating have a considerable risk of being lost in the future, irrespective of their risk of being lost in the previous four generations. 
Table 4

Genetic contribution based on pedigree, average allele frequency, probability of being lost and the risk of being in future generations of founders with extreme genetic contributions

\begin{tabular}{|c|c|c|c|c|c|c|c|}
\hline \multirow[t]{2}{*}{ ID } & \multirow[t]{2}{*}{ Sex } & \multirow{2}{*}{$\begin{array}{c}\text { Genetic } \\
\text { contribution }\end{array}$} & \multicolumn{2}{|c|}{ Allele frequency } & \multirow[t]{2}{*}{$\operatorname{Pr}(\text { lost })^{1}$} & \multirow[t]{2}{*}{$\operatorname{Pr}(\text { risk })^{2}$} & \multirow[t]{2}{*}{$\operatorname{Pr}(\text { risk|survive })^{3}$} \\
\hline & & & Average & $C V, \%$ & & & \\
\hline 263 & male & 0.0577 & 0.0568 & 54.5 & 0.0000 & 0.2818 & 0.2818 \\
\hline 513 & female & 0.0435 & 0.0441 & 62.4 & 0.0061 & 0.2455 & 0.2476 \\
\hline 186 & male & 0.0400 & 0.0397 & 67.2 & 0.0061 & 0.3697 & 0.3720 \\
\hline 220 & female & 0.0398 & 0.0419 & 69.9 & 0.0242 & 0.3091 & 0.3168 \\
\hline 219 & male & 0.0398 & 0.0387 & 71.3 & 0.0242 & 0.3515 & 0.3602 \\
\hline . & . & . & . & . & . & . & . \\
\hline . & . & . & . & . & . & . & . \\
\hline 505 & female & 0.0223 & 0.0223 & 58.1 & 0.0000 & 0.2727 & 0.2727 \\
\hline$\cdot$ & & $\cdot$ & . & · & . & · & · \\
\hline . & & & & & . & & . \\
\hline 231 & male & 0.0015 & 0.0015 & 48 & 0.5636 & 0.1152 & 0.2639 \\
\hline 147 & female & 0.0012 & 0.0008 & 39.4 & 0.7697 & 0.0545 & 0.2368 \\
\hline 187 & female & 0.0012 & 0.0013 & 32.4 & 0.7576 & 0.0545 & 0.2250 \\
\hline 148 & male & 0.0012 & 0.0012 & 45.2 & 0.7758 & 0.0485 & 0.2162 \\
\hline
\end{tabular}

${ }^{1}$ probability of allele extinction, ${ }^{2}$ probability of alleles being at high risk of extinction, ${ }^{3}$ probability of alleles surviving at critically low frequency

\section{Discussion}

\section{Retained alleles and founders}

Variable contributions of dropped founders into the last generation (Figure 2) show that 92 founders (59\%) have no descendants. Furthermore, about 87 and $95 \%$ of the alleles in the last generation is contributed by only 34 and 42 founders, respectively.

After increasing the average number of retained alleles in generation 1 (due to additional founders), there was a rapid decrease of alleles, which declined to 60 alleles in the last generation. These 60 segregating alleles could be assigned to the 128 alleles of the 64 founders contributing to the last generation. Although the number of alleles retained varied among replicates, the small coefficient of variation implies that the average over replicates is a good indicator for the number of retained alleles. The major reason for decreasing the founder' contribution and subsequently the average number of retained alleles and also increasing of coefficient of variation is the selection of progeny of superior founders as parents of the next generation. The rapid loss of alleles in early generations has also been reported (Honda et al. 2002, Rodrigáñez et al. 1998).

The proportion of founders in the category of less than $10 \%$ risk of being lost $(0-0.10)$ decreased from 0.89 in the base population to 0.15 in the last generation. In contrast, proportion of founders with a $50-100 \%$ probability of being lost increased from 0.11 to 0.26 . Generally, most of the founders still contributing to the last population were at risk of being lost in future generations.

Expectedly, the allele frequency averaged over replicates agreed with the genetic contribution. The small coefficients of variation imply that allele frequencies had a little variation around the average. For the 64 founders contributing to the last generation, founders with higher genetic contribution have lower probabilities of allele extinction 
$(\operatorname{Pr}($ lost $))$ and probability of allele extinction increased as genetic contribution decreased (Table 4). In the management of genetic diversity, Pr (lost) gives useful information, for example the low probability of allele extinction of the founder implies that alleles can be surely transmitted to the progenies (Trinderup et al. 1999).

The probability of allele extinction of the three founders with the highest genetic contributions was near zero but their surviving alleles had relatively high risks of future extinction $(0.28,0.24$ and 0.37$)$. In contrast, the probability of allele extinction of founders with the three lowest contributions were high $(>0.75)$ while their surviving alleles had a relatively low risk of future extinction. The high probability of allele extinction and the low risk of future extinction ( $\operatorname{Pr}($ risk|survive)) of alleles indicated that the alleles had passed a strong drift in the early generations. In contrast, the low probability of allele extinction and relative high risk of future extinction state that genetic contribution of founders are not fully informative for the distribution of allele frequency. This is in agreement with the results from Honda et al. (2002). It is also evident from comparing two founders of 263 and 505, each in which $\operatorname{Pr}($ lost $)=0$ for both of them and the risk of future extinction is the same but a genetic contribution of the former is about 2.5 times higher than that of the latter. Nevertheless, all founders have a significant probability of future extinction.

\section{Inbreeding and effective population size}

Results from Table 3 show that the effective population size decreases as inbreeding increases. However, the disproportionate contributions of the founders or ancestors is caused by many factors, such as population structure, mating policy, selection etc., but estimates of effective population size based on the increase or decrease in inbreeding would accurately reflect the genetic history of the population, namely the size of their founder population, their mating policy or bottlenecks due to abusive use of reproductive individuals. All these phenomena influence the pedigree of the individual and therefore are reflected in the increase or decrease of inbreeding (Gutie et al. 2008). In this study, the rate of inbreeding was $0.33 \%$ in generation 2 up to $1.1 \%$ in generation 4. This result is in agreement with Brah et al. (2001) while it is in opposite with Biedermann et al. (2009) that reported $4.62 \%$ and $7.12 \%$ at generation 2 and 3 , respectively for a population of white park cattle. These high figures of inbreeding are due to the small number of population (11 males and 33 females).

The effective population size is a very important parameter to monitor breeds and breeding programmes, as it affects the inbreeding depression and the loss of genetic variability. So the maintenance of genetic variation in breeding programmes is important for short- and long-term selection responses as well as for conservation purposes (Hill 2000). The large number of founders in the reference population and the low effective size in Table 2 is showing that some founders could be used more intensively than others, which is always a function of loss of genetic diversity. This is in agreement with a report of Vostrý et al. (2011) where 98, 139 and 168 founders were in the total reference population for three breeds of horse but the effective numbers of founders were only 43.14, 79.11 and 52.21, respectively. Meuwissen \& Woolliams (1994) suggested that if the effective population size is in the range of $31-250$, it would prevent the decline of fitness owing to inbreeding depression. Goddard \& Smith (1990) suggested 40 as a minimum effective size. 
A population with unequal representation of founders will contain less genetic variability than a population with the same number of founders, in which the founders have made equal contributions to future generations (Lacy 1989). This loss of variation is reflected by the loss of heterozygosity and the loss of allelic variants. Lower heterozygosity often results in lower average fitness of individuals (inbreeding depression) whereas a lack of allelic variants prevents long-term adaptive response to selection (Falconer et al. 1996).

We can estimate the distribution of allele frequencies and confidence intervals for the allele frequency by applying the gene dropping approach. This estimation can be valuable for observing trends in active breeding populations as have been shown by Manatrinon et al. (2009). Thus, for a sustainable development of response to selection, preservation of alleles from the lowest contributed founders should be an urgent task.

It can be concluded that gene dropping contributes to a detailed description of the genetic variation in a population and the risk of future loss of genetic variation. Thus, it is a valuable tool to optimize decisions to preserve genetic variability.

\section{References}

Baes C, Reinsch N (2008) TIGER: A software system for fine-mapping quantitative trait loci. Arch Tierz 51, 402-412

Biedermann G, Hecht W, Fandrey E, Rudolph H, Frölich K (2009) Population genetic analysis of White Park Cattle in Germany. Arch Tierz 52, 561-573

Brah GS, Chaudhary ML, Sandhu JS (2001) Direct and correlated responses to selection for 4-week body weight in two lines of Japanese quails. Arch Tierz 44, 99-108

Barker JSF (2001) Conservation and management of genetic diversity: a domestic animal perspective. Can J For Res 31, 588-595

Berg P (2010) EVA version 1.3. http://eva.agrsci.dk. [last accessed 13.03.2013]

Caballero A, Toro MA (2000) Interrelations between effective population size and other pedigree tools for the management of conserved populations. Genet Res 75, 331-343

Caballero A, Hill WG (1992) Effective Size of Nonrandom Mating Populations. Genetics 130, 909-916

Falconer DS, Mackay TFC (1996) Introduction to Quantitative Genetics. 4th ed., Longman, Essex, UK

Foose TJ, Lande R, Flesness NR, Rabb G, Read B (1986) Propagation plans. Zoo Biol 5, 139-146

Goddard MG, Smith C (1990) Optimum Number of Bull Sires In Dairy Cattle Breeding. J Dairy Sci 73, 1113-1122

Gutiérrez JP, Cervantes I, Molina A, Valera M, Goyache F (2008) Individual increase in inbreeding allows estimating effective sizes from pedigrees. Genet Sel Evol 40, 359-378

Hill WG (2000) Maintenance of quantitative genetic variation in animal breeding programmes. Livest Prod Sci 63, 99-109

Honda T, Nomura T, Fukushima M, Mukai F (2002) Gene dropping analysis of founder contributions in a closed Japanese black cattle population. Anim Sci J 73, 105-111

Khaldari M, Pakdel A, Mehrabani Yegane H, Nejati Javaremi A, Berg P (2010) Response to selection and genetic parameters of body and carcass weights in Japanese quail selected for 4-week body weight. Poult Sci 89, 1834-1841

Lacy RC (1989) Analysis of founder representation in pedigrees: Founder equivalents and founder genome equivalents. Zoo Biol 8, 111-123

Lange K, Cantor R, Horvath S, Perola M, Sabatti C, Sinsheimer J, Sobel E (2001) MENDEL version 4.0: a complete package for the exact genetic analysis of discrete traits in pedigree and population data sets. Am J Hum Genet 69 (Suppl.), A1886 
MacCluer JW, VandeBerg JL, Read B, Ryder OA (1986) Pedigree analysis by computer simulation. Zoo Biol 5, $147-160$

Manatrinon S, Egger-Danner C, Baumung R (2009) Estimating lethal allele frequencies in complex pedigrees via gene dropping approach using the example of Brown Swiss cattle. Arch Tierz 52, 230-242

Meuwissen THE, Woolliams JA (1994) Effective sizes of livestock populations to prevent a decline in fitness. Theor Appl Genet 89, 1019-1026

Nomura T, Honda T, Mukai F (2001) Inbreeding and effective population size of Japanese Black cattle. J Anim Sci 79, 366-370

Pérez Torrecillas C, Bozzi R, Negrini R, Filippini F, Giorgetti A (2002) Genetic variability of three Italian cattle breeds determined by parameters based on probabilities of gene origin. J Anim Breed Genet 119, 274-279

Ralls K, Harvey PH, Lyles AM (1986) Inbreeding in natural populations of birds and mammals. In: Soulé ME (ed.) Conservation Biology: The Science of Scarcity and Diversity. Sinauer Associates, Sunderland, MA, USA, 35-56

Rodrigáñez J, Toro MA, Rodriguez MC, Silió L (1998) Effect of founder allele survival and inbreeding depression on litter size in a closed line of Large White pigs. Anim Sci 67, 573-582

Suwanlee S, Baumung R, Sölkner J, Curik I (2007) Evaluation of ancestral inbreeding coefficients: Ballou's formula versus gene dropping. Conserv Genet 8, 489-495

Trinderup M, Jørgensen JN, Hansen M (1999) Conservation considerations on Danish Shorthorn Cattle using pedigree analysis. Anim Gen Res Inf 26, 27-33

Vostrý L, Čapková Z, Přibyl J, Hofmanová B, Vostrá Vydrová H, Mach K (2011) Population structure of Czech cold-blooded breeds of horses. Arch Tierz 54, 1-9

Wright S (1969) Evolution and the genetics of populations. Vol. 2: The theory of gene frequencies. University of Chicago Press, Chicago, USA

Wright S (1984) Evolution and the genetics of populations. Vol. 3: Experimental results and evolutionary deductions. Paperback ed., University of Chicago Press, Chicago, USA 